\title{
The Comprehensive Benefit Evaluation Model of Manual Inspection in Transmission Line
}

\author{
Jianfeng Huang ${ }^{1, a}$, Jing $\mathrm{Xu}^{2, \mathrm{~b}}$, Liqing Meng ${ }^{3, \mathrm{c}}$ and Zhongfu Qin ${ }^{4, \mathrm{~d}^{*}}$ \\ ${ }^{1,2}$ Maintenance branch of National network Zhejiang Electric Power Corporation,Zhejiang,Hangzhou \\ 311232, China \\ ${ }^{3,4}$ Zhejiang University,Zhejiang,Hangzhou 310058, China \\ ahjf8800@163.com,b282898098@qq.com, ${ }^{c} 1575840551 @ q q . c o m,{ }^{d}$ qinzhongfu@zju.edu.cn
}

Keywords: Manual inspection; Influence factors; Evaluation index system; Benefit evaluation

\begin{abstract}
Manual inspection is currently widely used, but the lack of an assessment of the benefits of the manual inspection system. This paper reviews the artificial transmission line inspection benefit influence factor, the extraction and discriminant analysis of factors, using expert scoring method to determine the effect factor.Then establishment of the manual inspection benefit evaluation index system, and use AHP method for index system of assignment.And finally establish the comprehensive benefit evaluation model for manual inspection. The model combines the manual inspection and evaluation index of impact factor that has a certain practical value.
\end{abstract}

\section{Introduction}

Nowadays, the operation management of the power network is becoming more and more integrated, intelligent, and information. Communication network scale unceasingly expands, the structure becomes more and more complex. Then, the power system maintenance management is becoming more and more important. Manual inspection methods are widely used. It's ability is strong to find tower foundation defect [1]. Transmission line helicopters and unmanned aerial vehicle inspection rise in recent years. In the world, there is not much research on the technology of the UAV [2]. At present, most of the inspection methods are still traditional manual inspection. Manual inspection can be carried out quickly and directly on some small hidden troubles and defects. It has more advantages in the discovery of defects in the tower foundation [3].The manual inspection efficiency characteristics as shown in Table 1.

\section{Analysis of the Influence Factors on the Performance of Transmission Line Inspection}

The Extraction of the Effect Factors of the Manual Inspection. This study, through literature review and in-depth theoretical research, fully consulted the opinions of power company experts at the same time, through brainstorming method extracted transmission line cooperative inspection effect influence factors are as follows [4]:

(1) Topographic factor: in transmission line erection, topographic condition is usually the decisive factor that determines the choice of erection method. Different terrain and topography, will change the choice of the mode of transportation. The different topographic condition also affects the work efficiency and work quality of the patrol personnel. It can be known that different terrain will have a decisive impact on the efficiency of transmission line inspection. The terrain factor mainly includes three kinds of topographic, the flat land, the mountainous region, the mountain river.

(2) Distance factor: distance inspection mainly includes two factors: per 100 kilometers car distance and human distance per 100 kilometers. Refers to the human distance is the joint inspection in vehicle section in place, the distance that manual need to walk to inspection; the car distance refers to the vehicle can travel distance before the inspection operation, the artificial walking. The car and human distance will directly affect the cost of inspection coordination. 
Table 1 Performance Characteristics of Manual Inspection

\begin{tabular}{cl}
\hline Benefit characteristic & \multicolumn{1}{c}{ Reasons } \\
\hline Relatively low quality & $\begin{array}{l}\text { Due to the inevitable human factors, the blind spot rate is relatively } \\
\text { large, and the recognition rate is relatively small. So its quality is } \\
\text { relatively low for other inspection methods. } \\
\text { Traditional manual inspection needs to spend a lot of time, the } \\
\text { efficiency is low. } \\
\text { Relatively low efficiency } \\
\text { Relatively low security } \\
\text { mountain climbing and field work are needed. So the risk of personal } \\
\text { injury is high. } \\
\text { The cost of manual inspection is much lower than that of unmanned } \\
\text { aerial vehicles and helicopters. The cost of its line of inspection tour } \\
\text { operators are basically only the relevant costs (wages, benefits, } \\
\text { subsidies, etc.); The cost of equipment inspection (mainly including } \\
\text { the inspection of vehicles and equipment inspection personnel) is } \\
\text { relatively low. }\end{array}$ \\
\hline
\end{tabular}

(3) Tower height: transmission line tower height generally includes three categories; the tower which is 40 meters and below, the tower which is 40 to 70 meters, the tower which is more than 70 meters. If you need to check the tower through climbing, The efficiency of the inspection is obviously influenced by different height.

(4) Tower type factor: there are many types of tower. Most common are straight line tower and resistance to tension tower. They also affect the inspection efficiency obviously. Because of their different inspection scope and the difficulty of inspection. Therefore, the efficiency of the inspection work for the two tower type is not the same.

(5) tower base / $100 \mathrm{~km}$ factor: the tower base per hundred kilometers is different, which will have a direct impact on inspection's time and quality indicators. Therefore, the efficiency of inspection will have a greater impact.

(6) Vegetation factor: the difference of vegetation will directly affect the performance of inspection. In this study, the vegetation factor is divided into four kinds: grassland, bare land, forests and bushes. The difference of vegetation distribution will directly affect the speed, quality and safety of inspection, so as to affect the efficiency of inspection.

(7) Patrol classification factor: transmission line inspection operations in different types of inspection in the performance of the inspection has a lot of differences. Power network engineering inspection is generally divided into three types of daily inspection, emergency inspection and fault inspection. According to different inspections, inspection costs are not the same, the efficiency of inspection is also different.

(8) Operating mode factor: The different inspection operation mode is one of the factors that affect the inspection efficiency. The operation methods of transmission line inspection usually include two kinds of boarding pole inspection and ground inspection. The time and cost required to board the pole and the ground is not the same. The effect of inspection is also very different.

(9) Weather factor: Weather factor is an important influence factor for inspection. Weather conditions are divided into spring and autumn daily, summer daily, winter daily, storm daily and snow daily. They will affect the quality, safety, efficiency and cost of inspection.

(10) Technical experience factor: Each person's technical experience is different. Skilled and experienced people and Technical experience of stranger's efficiency is not the same in the inspection work.

(11) Inspection mode factor: At present, the main inspection methods of manual inspection operation of transmission line in power network engineering are collective segment. The number of the inspection will affect the speed and cost and security of inspection. Therefore, the inspection mode is also an important factor affecting the efficiency of transmission line inspection.

(12) Inspection object factor: The main objects of general inspection are "ontology" and "channel" "."Ontology" is mainly refers to the transmission line tower, lines and ancillary facilities. 
"Channel" is mainly refers to the status of transmission line. The inspection object is different, the inspection efficiency, the safety factor, the cost is not the same. Therefore, with the change of the inspection object the inspection efficiency is not the same.

(13) Road condition factor: The road condition which affects the efficiency of the inspection is mainly refers to the condition of the road of the moving part and the manual running part. Such as highway impact on car distance. Different road conditions, car and human distance is different. The car and human distance's change will directly affect the cost of inspection

(14) Geologic factor: Geological factors, such as mineral, geological structure and so on. Geological structure generally includes two basic forms of fault and fold. According to the relevant expert advice, if the geological condition is different, sometimes it can affect the defect identification and channel inspection of the inspection.

(15) Continuous factor of inspections: The continuity of the inspection mainly include continuous inspection and interrupted inspection, etc. The efficiency of continuous and intermittent inspection is different.

(16) Failure frequency factor : Fault frequency is the frequency of transmission line fault.

(17) Comprehensive evaluation factor: According to the relevant expert advice, this factor mainly includes the applicability, the control convenience and so on.

(18) Ontology factor: the ontology factor consider the tower height, tower type, Loop number and conductor splitting number. Ontology is the target of inspection work, is the object of inspection. The time and cost of different inspection objects are different.

(19) Weight: because each index is different, so the different index of the efficiency of each index will affect the size of the benefit.

(20) Effect: The effect of transmission line inspection operation is generally refers to the recognition rate of defects, etc. In this study, the recognition rate of defects is divided into the defect recognition rate of ontology, the defect recognition rate of channel, fault recognition rate

(21) Quality: the quality factor and the effect factor have similar connotation. There is a slight difference between the quality and the effect. Usually, the effect includes quality, efficiency, etc. The research for the quality of inspection is mainly from three dimensions of blind spot rate and identification rate of the tower, line channel and fault.

(22) Security: this study divided the safety of the inspection indicators into three kinds: road transportation safety, human transportation security and Board check safety. These safety factors have a direct impact on the effectiveness of inspection.

(23) Efficiency: this study combined with the specific situation of transmission line inspection operations, the efficiency of inspection is divided into three categories, the efficiency of the motor transport, the efficiency of human transport, and the efficiency of manual inspection. The efficiency of inspection can be used as an important reference to measure the efficiency of inspection.

(24) Cost: The inspection cost mainly includes two kinds of direct and indirect costs. Direct costs include car transport costs and the cost of people. Indirect costs include inspection equipment acquisition costs and maintenance costs, equipment maintenance and management costs, energy consumption, logistics, training, software costs, communication services, information processing (pre collection, post-processing), etc. The inspection cost reflects the economic performance of the inspection, which is an important factor to affect the efficiency of the inspection.

The Adjustment of the Effect Factors of The Manual Inspection. Through the finishing of the last section, the factors that affect the inspection operation are 24, topographic factor, distance factor, Tower height factor, tower type factor, tower base / $100 \mathrm{~km}$ factor, vegetation factor, patrol classification factor, operating mode factor, weather factor, technical experience factor, inspection mode factor, Inspection object factor, road condition factor, geologic factor, continuous factor of inspections, failure frequency factor, comprehensive evaluation factor, ontology factor, weight, effect, quality, security, efficiency, cost [5], respectively. 
Table 2 Influence Factors of Collaborative Inspection

\begin{tabular}{|c|c|c|c|}
\hline Before adjustment & After adjustment & $\begin{array}{l}\text { Arrange } \\
\text { mode }\end{array}$ & Reason for adjustment \\
\hline Topographic factor & $\begin{array}{l}\text { Topographic } \\
\text { condition }\end{array}$ & Retain & Text representation format unity \\
\hline Distance factor, & Inspection distance & Retain & Text representation format unity \\
\hline Tower height factor & Tower height & Retain & Text representation format unity \\
\hline Tower type factor & Tower type & Retain & Text representation format unity \\
\hline $\begin{array}{l}\text { Tower base / } 100 \mathrm{~km} \\
\text { factor }\end{array}$ & Tower base & Retain & Text representation format unity \\
\hline Vegetation factor & $\begin{array}{l}\text { Vegetation } \\
\text { condition }\end{array}$ & Retain & Text representation format unity \\
\hline $\begin{array}{l}\text { Patrol classification } \\
\text { factor, }\end{array}$ & Inspection category & Retain & $\begin{array}{l}\text { Text representation } \\
\text { specification }\end{array}$ \\
\hline Operating mode factor & Operating mode & Retain & Important influence factor \\
\hline Weather factor & Weather condition & Retain & Important influence factor \\
\hline $\begin{array}{l}\text { Technical experience } \\
\text { factor }\end{array}$ & $\begin{array}{l}\text { Technical } \\
\text { experience }\end{array}$ & Retain & Important influence factor \\
\hline Inspection mode factor & Inspection category & Retain & Important influence factor \\
\hline Inspection object factor & Inspection object & Retain & Important influence factor \\
\hline $\begin{array}{l}\text { Continuous factor of } \\
\text { inspections }\end{array}$ & $\begin{array}{l}\text { Continuous factor } \\
\text { of inspections }\end{array}$ & Retain & Important influence factor \\
\hline Road condition factor & Road condition & Retain & Text representation format unity \\
\hline Geologic factor & & Delete & $\begin{array}{l}\text { Influence degree and influence } \\
\text { probability is low }\end{array}$ \\
\hline Failure frequency factor & & Merge & Under the inspection category \\
\hline $\begin{array}{l}\text { Comprehensive } \\
\text { evaluation factor }\end{array}$ & $\begin{array}{l}\text { Comprehensive } \\
\text { evaluation }\end{array}$ & Retain & Important influence factor \\
\hline Weight & Weight & Unchanged & Important influence factor \\
\hline Effect & & Merge & Merge with the quality factor \\
\hline Quality & Quality & Delete & This indicator impacts the last result \\
\hline Security & Security & Delete & This indicator impacts the last result \\
\hline Cost & Cost & Delete & This indicator impacts the last result \\
\hline Efficiency & Efficiency & Delete & This indicator impacts the last result \\
\hline Ontology factor & Inspection object & Merge & Merge with the inspection object \\
\hline
\end{tabular}

The influencing factors of the inspection work after the discrimination are 17: Topographic condition, Inspection distance, Height, Tower type, Tower base, Vegetation condition, Inspection category, Operating mode, Weather condition, Technical experience, Road condition ,Comprehensive evaluation, Inspection object, Continuous factor of inspections, Efficiency, Inspection object, Weight.

The Classification of the Effect Factors of the Manual Inspection. Through the last section we can know that factors that affect the efficiency of the evaluation objects are numerous and influence situation complex in the evaluation of transmission line inspection. Therefore, in the calculation of hierarchical index, We need to make a reasonable classification of the impact factor and the impact factor of the set.

In the initial study, we discussed the influence factors with experts many times. After many arguments to get a lot of impact factors. After classification, there are 6 major categories. The names of these categories are normalized in the end. We obtain the influence factors of transmission line benefit. They are Topographic condition, Tower height, Weather condition, Pole position, Inspection method, Index weight.

According to the reference of numerous literatures and the analysis of practical problems, 
Combined expert opinion, this study used retain the impact factor, delete the impact factor, merge the impact factor, conversion the impact factor, increase the impact factor and other ways to classified influence factor [6]. The influence factors are classified and the results are shown in Table 3.

Table 3 categories of factors of manual inspection results

\begin{tabular}{ll}
\hline \multicolumn{1}{c}{ Primary influence factors } & \multicolumn{1}{c}{ Two influence factors } \\
\hline Inspection method & $\begin{array}{l}\text { Routine inspection、Fault inspection、Emergency } \\
\text { inspection } \\
\text { Flat ground( D1 ) Mountain and hill( D2 ). Mountain } \\
\text { Topographic condition(D) }\end{array}$ \\
Weather condition(W) & Good weather ( W1 )、Bad weather ( W2 ) \\
Seasonal condition(S) & Spring and autumn(S1)、Summer(S2)、Winter(S3) \\
Tower height(G) & Low tower(G1)、Middle tower(G2)、High tower (G3) \\
Tower type(T) & $\begin{array}{l}\text { Straight line tower (T1)、Resistance to tension } \\
\text { tower(T2) } \\
\text { Conductor splitting number is 1、2、4、6、8 (F1、F2、 }\end{array}$ \\
Conductor splitting number(F) & F3、F4、F5) \\
Loop number(H) & Loop number is 1、2、4 ( H1、H2、H3 ) \\
\hline
\end{tabular}

The Coefficient of Effect Factors of the Manual Inspection. Table 3 shows the influence factors of the performance of the manual inspection. Each influence factor will have different influence on the inspection efficiency. There will be different effects in different inspection methods. In this paper, the expert scoring method is used to provide the basis for obtaining the influence factor coefficient.

\section{The Establishment and the Assignment of the Evaluation Index System of Manual Inspection Benefit about Electric Transmission Line}

The Principle of Establishing the Evaluation Index System of Manual Inspection Benefit. The evaluation index system of manual inspection benefit is selected scientifically, comprehensively and systematically and appropriately. Scientific principle means that indexes must be able to reflect manual inspection benefit. Comprehensive principle means indexes being listed must be comprehensive. Systematic principle means indexes are classified into different levels systematically. And appropriate principle means indexes could assess manual inspection benefit effectively.

Construct of the Evaluation Index System of Manual Inspection Benefit. Extract evaluation indexes. According to industry experts, we adopt the brainstorming and got dozens of different indexes firstly. On the basis of comprehensive analysis, we have carried on selection and induction to these indexes. Than not appropriate indexes are excluded and repetitive indexes are merged. Finally, we get the five indexes - benefit, quality, safety, efficiency and cost.

Classify evaluation indexes. According to the analysis of the previous section, the evaluation index is divided into three levels. The first level is benefit, the second one are quality, safety, efficiency and cost and different three-level index contained above second level. These indexes are cleared up into a convenient form, As Table 4. 
Table 4 Performance Evaluation Index System of Transmission Line Collaborative Inspection

\begin{tabular}{|c|c|c|c|}
\hline First level index & Second level index & & hird level index \\
\hline \multirow{14}{*}{ Benfit ( B ) } & \multirow{6}{*}{ Quilty } & \multirow{2}{*}{ Line ontology } & $\begin{array}{l}\text { Above tower base bottle defect } \\
\text { recognition rate, } \\
\text { Grounded defect recognition } \\
\text { rate ( } 1 \text { 1) }\end{array}$ \\
\hline & & & $\begin{array}{l}\text { Under tower base bottle defect } \\
\text { recognition rate }(x 2)\end{array}$ \\
\hline & & \multirow[b]{2}{*}{$\begin{array}{l}\text { Affiliated } \\
\text { Facilities }\end{array}$} & Devices identification rate( $\mathrm{x} 3$ ) \\
\hline & & & $\begin{array}{l}\text { Signs, logos recognition rate } \\
(\mathrm{x} 4)\end{array}$ \\
\hline & & \multirow{2}{*}{$\begin{array}{l}\text { Channel } \\
\text { Environment }\end{array}$} & $\begin{array}{l}\text { Buildings, trees recognition } \\
\text { rate }(x 5)\end{array}$ \\
\hline & & & $\begin{array}{l}\text { Infrastructure recognition rate } \\
(\mathrm{x} 6)\end{array}$ \\
\hline & \multirow{3}{*}{ Safety } & \multicolumn{2}{|c|}{ Life safety $(x 7)$} \\
\hline & & \multicolumn{2}{|c|}{ Equipment safety ( x8 ) } \\
\hline & & \multicolumn{2}{|c|}{ Ontology safety ( x9 ) } \\
\hline & \multirow{2}{*}{ Efficiency } & \multicolumn{2}{|c|}{ Inspection efficiency ( x10 ) } \\
\hline & & \multicolumn{2}{|c|}{ Motor efficiency ( x11 ) } \\
\hline & \multirow{3}{*}{ Cost } & \multicolumn{2}{|c|}{ Inspection cost ( $\mathrm{x} 12)$} \\
\hline & & \multicolumn{2}{|c|}{ Equipment cost ( x13) } \\
\hline & & \multicolumn{2}{|c|}{ Training cost (x14) } \\
\hline
\end{tabular}

Evaluate Influence Factors of manual Inspection. This study selected analytic hierarchy process (AHP) [9 10] to evaluate evaluation indexes of manual inspection benefit and set. Weight. Its basic principle is to identify complex problem down into several levels. Experts and policymakers indicators evaluate important degree between two indexes and give a score step by step. Contribution degree of The lower index on the to the upper one is by calculating the characteristic vector judgment matrix and get importance of grassroots indexes to the overall goal, namely weight. Valuation of Influence factors of manual Inspection as showed in Table 5. 
Table 5 Evaluation Index System of Manual Inspection

\begin{tabular}{lll}
\hline Index & Index code & Index value \\
\hline Above tower base bottle defect recognition rate & x1 & 0.150 \\
Grounded defect recognition rate & & \\
Under tower base bottle defect recognition rate & x2 & 0.050 \\
Devices identification rate & x3 & 0.040 \\
Signs, logos recognition rate & x4 & 0.025 \\
Buildings, trees recognition rate & x5 & 0.020 \\
Infrastructure recognition rate & x6 & 0.015 \\
Life safety & x7 & 0.100 \\
Equipment safety & x8 & 0.015 \\
Ontology safety & x9 & 0.035 \\
Inspection efficiency & x10 & 0.120 \\
Motor efficiency & x11 & 0.030 \\
Inspection cost & x12 & 0.250 \\
Equipment cost & x13 & 0.080 \\
Training cost & x14 & 0.070 \\
\hline
\end{tabular}

\section{Manual Inspection Comprehensive Benefit Evaluation Model}

Manual inspection comprehensive benefit is a blend of evaluation index system of manual inspection and influence factors of inspection. Manual inspection comprehensive benefit evaluation model are as follows:

Regular Inspection:

$$
\begin{aligned}
& \mathrm{B}^{\mathrm{c}}= \sum_{\mathrm{n}=1}^{14} \mathrm{X}_{\mathrm{n}}^{\mathrm{c}} \\
& \mathrm{X}_{\mathrm{n}}^{\mathrm{c}}=\mathrm{x}_{\mathrm{n}} \times \mathrm{D}^{\mathrm{c}} \times \mathrm{W}^{\mathrm{c}} \times \mathrm{S}^{\mathrm{c}} \times \mathrm{G}^{\mathrm{c}} \times \mathrm{T}^{\mathrm{c}} \times \mathrm{F}^{\mathrm{c}} \times \mathrm{H}^{\mathrm{c}}
\end{aligned}
$$

Fault Inspection:

$$
\begin{aligned}
& \mathrm{B}^{\mathrm{z}}= \sum_{\mathrm{n}=1}^{14} \mathrm{X}_{\mathrm{n}}^{\mathrm{z}} \\
& \mathrm{X}_{\mathrm{n}}^{\mathrm{z}}=\mathrm{x}_{\mathrm{n}} \times \mathrm{D}^{\mathrm{z}} \times \mathrm{W}^{\mathrm{z}} \times \mathrm{S}^{\mathrm{z}} \times \mathrm{G}^{\mathrm{z}} \times \mathrm{T}^{\mathrm{z}} \times \mathrm{F}^{\mathrm{z}} \times \mathrm{H}^{\mathrm{z}}
\end{aligned}
$$

Emergency Inspection:

$$
\begin{aligned}
& \mathrm{B}^{\mathrm{y}}=\sum_{\mathrm{n}=1}^{14} \mathrm{X}_{\mathrm{n}}^{\mathrm{y}} \\
& \mathrm{X}_{\mathrm{n}}^{\mathrm{y}}=\mathrm{x}_{\mathrm{n}} \times \mathrm{D}^{\mathrm{y}} \times \mathrm{W}^{\mathrm{y}} \times \mathrm{S}^{\mathrm{y}} \times \mathrm{G}^{\mathrm{y}} \times \mathrm{T}^{\mathrm{y}} \times \mathrm{F}^{\mathrm{y}} \times \mathrm{H}^{\mathrm{y}}
\end{aligned}
$$

\section{Summary}

This study aims to build transmission line manual inspection Comprehensive Assessment Modeling by analyzing the characteristics of the current manual inspection of China and extracting efficiency of a manual inspection shadow impact and building patrol benefit evaluation index system. The article combines inspection under the influence of factors and assessment factor index value to build comprehensive assessment Modeling. This model has a certain practicality for the actual transmission line having a manual inspection efficiency rating guide. However, the present study does not involve unmanned aerial vehicles and helicopters patrol, unmanned aerial vehicles and helicopters patrol effectiveness evaluation will be the focus of future research directions. 


\section{References}

[1] J. Li, W.J. Li, K. Xiao and J.G. Liang: Power communication device state evaluation method based on fuzzy comprehensive evaluation [J] Southern Power System Technology, 2014,05: 56-60.

[2] X.B. Chen, Z.J. Xu, et al: Unmanned aircraft Transmission Line Inspection Technique [J] China Southern Power Grid Technology .2008,2 (6): 57- 60.

[3] LEW R .The future of power line inspection [J]. Electrical World, 2000,214 (5): 25- 27.

[4] P. Yun, Q. Mao and L. Jian: Overhead transmission lines helicopters, unmanned aerial vehicles and ground patrol doing research and complementary mechanism of [J]. Guangxi Electric Power, 2013,05: 72-75.

[5] K.X. Wu: Zhe jiang Province transmission line operation and maintenance Maintenance Management Model [D]. Zhe Jiang University of Technology, 2014.

[6] Z. Li, Y. Liu, Hay ward R, et al: Knowledge-based power line detection for UAV surveillance and inspection systems, in International Conference of Image and Vision Computing New Zealand, Christchurch, 2008: 1- 6.

[7] L.P. Yue, X.Y. Zhang: Bow of transmission line inspection mode drones and doing[J].Collaborative Electric Age, 2014,09: 81-83 .

[8] T. Zhang: Consider overhead transmission lines reliability assessment and maintenance decision method special section[D]. Chong Qing University, 2014.

[9] C.Y. Zhao,Y.H.Hu, F. Tian, P. Sun: The analytic hierarchy process in the application of the supply chain management in the selection of suppliers $[\mathrm{J}]$. Shenyang electric power college newspaper, 2003, 2:51-53.

[10]R.J. Guo, W.X. Wang, G.B. Zhu: The analytic hierarchy process in the application of virtual enterprise partner selection [J] Machinery, 2003, 03:20-22. 